\title{
VAGINAL FLUID pH FOR DETECTION OF BACTERIAL VAGINOSIS
}

\section{Dr. Akshatha Rao* \\ Dr. Anil S Baipadithaya}

\section{Dr. Geeta Doppa}

\section{Dr. Ravikanth GO}

\section{Dr. Namrata}

Postgraduate student, Dept. of Obstetrics and Gynaecology, KVG Medical College and Hospital, Sullia, Karnataka, India. ${ }^{*}$ Corresponding Author

Associate Professor, Department of Obstetrics and Gynaecology, KVG Medical College and Hospital, Sullia, Karnataka, India.

Professor and HOD, Department of Obstetrics and Gynaecology, KVG Medical College and Hospital, Sullia, Karnataka, India.

Associate Professor, Dept. of Obstetrics and Gynaecology, KVG Medical College and Hospital, Sullia, Karnataka, India.

Associate Professor, Dept. of Microbiology, KVG Medical College and Hospital, Sullia, Karnataka, India.

ABSTRACT Background: Bacterial vaginosis (BV) is the most common cause of abnormal vaginal discharge and malodor in women of reproductive age. BV reflects a shift in normal vaginal flora to mixed anaerobic and gram negative flora increasing the vaginal $\mathrm{pH}$, which eventually increases vulnerability to sexually transmitted diseases and complicates pregnancies. The objective of this study was to evaluate the accuracy of vaginal $\mathrm{pH}$ individually and its combinations with other factors of Amsel's criteria to diagnose bacterial vaginosis.

Methods: The study was carried out in gynaecology department in K.V.G. Medical College Hospital, Sullia over a period of 6 months. Vaginal swabs of women complaining of white discharge pv were collected using 2 sterile swabs. One, to prepare wet mount and to assess for amine test, other for Grams staining. Vaginal pH was measured using pH strips. A total of 105 patients were checked for the confirmation of Bacterial Vaginosis according to the Amsel's Criteria and Nugent's Scoring.

Results: The prevalence of bacterial vaginosis is 39\% by Amsel's criteria and 33\% by Nugent's scoring. Comparing with Nugent scoring methods, the clinical diagnosis by Amsel's criteria had sensitivity of $85.3 \%$, specificity of $95 \%$. Vaginal pH individually had a sensitivity of only $73.4 \%$. Combination of vaginal $\mathrm{pH}$ test with clue cells had highest sensitivity while vaginal $\mathrm{pH}$ test with whiff test was comparatively less sensitive.

Conclusion: Amsel's criteria diagnosis can be simplified by using a combination of 2 criteria, $\mathrm{pH}$ of secretions and presence of clue cells but if lab equipment is unavailable, using vaginal fluid $\mathrm{pH}$ can still produce moderately accurate results.

\section{KEYWORDS :}

\section{INTRODUCTION:}

Bacterial vaginosis (BV) is the most common cause of vaginal discharge and malodor in women of reproductive age. ${ }^{1}$ Bacterial vaginosis reflects a shift in normal vaginal flora from hydrogen peroxide producing lactobacilli to mixed flora like Gardnerella vaginalis, mycoplasmas and anaerobes such as Mobiluncus, Peptostreptococcus. ${ }^{2}$ This polymicrobial superficial vaginal infection involving loss of the normal lactobacilli causes increase in vaginal $\mathrm{pH}(>4.5)$

There is no known reason why it is so common. Though closely related to sexual intercourse it is not termed as a sexually transmitted disease because of its high prevalence in sexually inactive women. ${ }^{4}$ Recent study shows association between high vaginal $\mathrm{pH}$ and cervicovaginal inflammatory cytokines that are implicated in increased vulnerability to HIV, sexually transmitted diseases, preterm delivery in asymptomatic women with BV. ${ }^{5}$ BV has been linked to low birth weight infants, preterm delivery, chorioamnionitis, post hysterectomy cuff cellulitis, post-surgical endometritis, endometritis following vaginal delivery, and PID. Hence it is critical to diagnose and treat women affected with BV.

Risk factors include oral sex, douching, black race, cigarette smoking, sexual intercourse during menstruation, intrauterine device, early age of sexual intercourse, new or multiple sexual partners, sexual activity with other women. ${ }^{2}$ Most of the patients are asymptomatic. Some patients show symptoms like increase in white discharge which appears homogeneous, is low in viscosity and evenly coats the vaginal mucosa and there is a characteristic fishy smelling vaginal odour. The patients may also experience itching and burning in the vaginal area.
The $\mathrm{pH}$ of vaginal secretions is maintained between 3.8 and 4.5 in healthy women and remains within range even during menstruation. A pH of 4.5 or less signifies the absence of vaginitis, whereas a $\mathrm{pH}$ of more than 4.5 is classified as vaginitis as the presence of $\mathrm{BV}$ leads to high $\mathrm{pH}$ of vaginal secretion. Other factors that are known to disturb this $\mathrm{pH}$ are antibiotic treatment, ${ }^{7}$ inflammatory reactions and even intercourse ${ }^{7}$ can lead to the elevated $\mathrm{pH}$. In postmenopausal women the $\mathrm{pH}$ of vaginal secretion is increased, which is attributed to the decreasing level of estrogen.

Rapid screening with available resource is essential for a favorable health care outcome. Classical initial method of BV diagnosis was done by isolation of $\mathrm{G}$. vaginalis from clinical specimen. Later on, with the advent of the anaerobic culture techniques other organisms were also detected from specimens. Amsel's clinical diagnosis and gram stain evaluation by Nugent methods are mostly used worldwide particularly in developing countries.

The Nugent scoring test requires health care experts, laboratory support, and also access to a high-power microscopy to obtain timely results for the diagnosis of BV. Since these necessities are not always available in rural places, it is important to have simple and reliable clinical criteria that clinicians can use in practice. Therefore, knowing the best diagnostic approach in a given area using the available resource helps in deciding the preferred method for diagnosis.

OBJECTIVES OF THE STUDY: To evaluate the accuracy of vaginal $\mathrm{pH}$ individually and its combinations with other factors of Amsel's criteria to diagnose bacterial vaginosis. 
AMSEL'S CRITERIA: Amsel's criteria are used for the clinical diagnosis of $\mathrm{BV}$, and a positive diagnosis is made when at least three of the four following criteria are present:

A thin homogeneous vaginal discharge

Vaginal $\mathrm{pH} \geq 4.5$

Positive whiff test

The presence of clue cells on wet mount.

\section{SOURCE OF DATA:}

This hospital based study was carried out in gynaecology department in K.V.G. Medical College Hospital, Sullia over a period of 6 months. Data was collected in a pre-designed form.

\section{METHODS OF COLLECTION OF DATA:}

Ethical committee clearance was obtained. Data was collected after taking written informed consent from the properly selected patients.

First, thorough history as per pre-prepared questionnaire, then clinical examination and laboratory tests were done. Those women complaining of white discharge per vagina were included in the study. Vaginal $\mathrm{pH}$ was measured using $\mathrm{pH}$ strips. Vaginal discharge was collected using 2 sterile cotton tip swabs. One, to prepare wet mount, then assess for amine test, other for Gram's staining. A total of 105 patients were checked for the confirmation of Bacterial Vaginosis according to the Amsel's Criteria and Nugent's scoring.

\section{INCLUSION CRITERIA:}

Patients complaining of excessive vaginal discharge in the age group of $18-45$ years.

\section{EXCLUSION CRITERIA:}

Pregnant women

Known diabetics

On antibiotic treatment

History of intercourse on previous night

Per vaginal bleeding

Clinical diagnosis of bacterial vaginosis was considered positive if three of the four criteria in Amsel's diagnosis were met.

Gram stain diagnosis was based on a criterion score described by Nugent and considered positive if the score was $7-10$. The Nugent criteria score vaginal flora as normal (0-3), intermediate (4-6), and bacterial vaginosis (7-10).

STATISTICAL ANALYSIS: - All relevant clinical information of the cases were recorded systematically in the predesigned clinical data sheet. Data was analyzed using SPSS (11.0).

A descriptive analysis was done and frequency, percentages and ratios were computed from the data.

Sensitivity, specificity, positive and negative predictive value of Amsel's criteria was calculated.

\section{RESULTS:}

The age range of the study participants was $18-45$ with mean age was 32.5 years. [Table 1]

The prevalence of bacterial vaginosis was 39\% by Amsel's criteria and $33 \%$ by Nugent scoring. Amsel's criteria had sensitivity of $85.3 \%$ and a specificity of $95.3 \%$ when compared using Gram stain evaluated by Nugent scoring method as standard. [Table 2]

When we compare individual Amsel's criteria with Nugent scoring, in the present study we found that presence of clue cells was the criteria with the highest sensitivity of $89.5 \%$ and specificity of $75.6 \%$. [Table 3]
The sensitivity of vaginal $\mathrm{pH}$ and Whiff test was the same $73.7 \%$. However, PPV and NPV of vaginal $\mathrm{pH}$ was higher in our study.

All criteria had high negative predictive value ranging between $88 \%-91 \%$.

When combination of two Amsel's criteria was considered, with vaginal $\mathrm{pH}$ along with presence of Clue cells, had the highest sensitivity of $81.6 \%$ with a PPV of $96 \%$ and a NPV of 94\%. [Table 4] [Graph 10]

Combination of vaginal $\mathrm{pH}$ along with positive whiff test had a sensitivity of $73.7 \%$ with a PPV of $89 \%$ and a NPV of $87 \%$. [Graph 11]

\section{DISCUSSION:}

The clinical diagnosis of bacterial vaginosis has long been made using Amsel's criteria or Nugent's criteria.

A study on the comparison of Pap smear and microbiological pattern in Bacterial Vaginosis done in Rajarajeshwari Medical College in Bangalore showed BV had a prevalence of $34.6 \%$ which is closely similar to ours which is $33 \%$ confirmed by Nugent's scoring method.

The flora of the female genital tract varies with the $\mathrm{pH}$ and estrogen concentration, which is dependent on the age of the host. In this study all women were within the reproductive age group, no one had diabetes, were not on any medication, and did not have sexual act on the previous night. These inclusion criteria were taken into consideration.

When we correlate any two of Amsel's criteria the presence of clue cells in vaginal wet mount and high vaginal $\mathrm{pH}$ had the greatest sensitivity (81.6\%) and specificity (66.5\%), respectively with high PPV and NPV.

That of vaginal $\mathrm{pH}$ with Whiff Test had a comparatively lower sensitivity, PPV and NPV.

In conditions where there is not enough time and gram stain procedure is cumbersome, combination of vaginal $\mathrm{pH}$ and clue cells detection can be used.

Therefore, combining $\mathrm{pH}$ tests with other symptoms can enhance the accuracy of the test in diagnosis of various infectious conditions. Various factors such as simultaneous infections of vagina and cervical mucus might have influence on these criteria.

From individual criteria for predicting the gram stain result, clue cells detection from wet mount microscopic examination is the most reliable predictor of bacterial vaginosis. It had a higher sensitivity(89.5\%), specificity(75.6\%) and positive and negative predictive value. This is consistent with the study done by Mittal V et al.(2012).

Second most reliable predictor is alkaline vaginal $\mathrm{pH}$ with a significant sensitivity of $73.7 \%$ and higher PPV and NPV than that of whiff test. This is consistent with Dadhwal et al who also states that the decrease in sensitivity of whiff test may attribute to subjective nature of the test due sensation ability of the person doing the test.

Lack of acidity allows the proliferation of other organisms (microbial dysbiosis) which may be causative of underlying disease. As lactobacilli play a key role in acidifying the vagina, it is not surprising that vaginal $\mathrm{pH}$ remains part of Amsel's criteria in making the clinical diagnosis of bacterial vaginosis. 
In a study by Mania Pramanik et al. done in KEM hospital in Mumbai, vaginal $\mathrm{pH}$ had a $100 \% \mathrm{PPV}$, as a tool for diagnosis of BV. However, in our study clue cells has the highest PPV and NPV in diagnosis of BV.

This difference in sensitivity and predictive value may be due to difference of study population, clinical case and higher prevalence of bacterial vaginosis.

\section{CONCLUSIONS:}

In patients complaining of white discharge per vagina, diagnosis by Amsel's criteria can be simplified by using a combination of 2 criteria, a high vaginal $\mathrm{pH}$ and the presence of clue cells on wet mount slide.

In our study high vaginal $\mathrm{pH}$ correlated well with the occurrence of BV. In developing countries microscopes are not readily available in all clinical settings and hence an easily performed $\mathrm{pH}$ evaluation in the OPD setting could be safely used to diagnose BV.

Table 1: Age Distribution Of The Patients Study.

\begin{tabular}{|l|l|l|}
\hline Age Distribution & Number OF Patients & $\%$ \\
\hline$<25$ & 7 & 6.66 \\
\hline $26-30$ & 35 & 33.3 \\
\hline $31-35$ & 37 & 35.23 \\
\hline $36-40$ & 11 & 19.47 \\
\hline$>41$ & 15 & 14.28 \\
\hline Total & 105 & 100.0 \\
\hline
\end{tabular}

Table 2: Nugents Score

\begin{tabular}{|l|l|l|l|l|l|l|}
\hline & $\begin{array}{l}\text { NUGENTS } \\
\text { SCORE }\end{array}$ & Sensitivity & Specificity & PPV & \multicolumn{2}{|l|}{ NPV } \\
\hline $\begin{array}{l}\text { AMSEL'S } \\
\text { Criteria }\end{array}$ & 35 & 03 & 85.36 & 95.31 & 92.1 & 91.5 \\
\hline & 6 & 61 & & & & \\
\hline Total & 41 & 64 & & & & \\
\hline
\end{tabular}

Table 3: Diagnostic Accuracy Of Individual Clinical Criteria \begin{tabular}{|l|l|l|l|l|}
\hline AMSEL Criteria & Sensitivity & Specificity & PPV & NPV \\
\hline
\end{tabular}

\begin{tabular}{|l|l|l|l|l|}
\hline Vaginal pH & 73.7 & 60 & 61 & 90 \\
\hline Whiff & 73.7 & 73.3 & 60 & 88 \\
\hline Clue Cell & 89.5 & 75.6 & 90 & 91 \\
\hline
\end{tabular}

Table 4: Diagnostic Accuracy Of Combintion Of Two Criteria

\begin{tabular}{|l|l|l|l|l|}
\hline AMSEL Criteria & Sensitivity & Specificity & PPV & NPV \\
\hline $\begin{array}{l}\text { Vaginal PH + Clue } \\
\text { Cells }\end{array}$ & $81.6 \%$ & $66.85 \%$ & 96.12 & 94.23 \\
\hline $\begin{array}{l}\text { Vaginal PH + Whiff } \\
\text { Test }\end{array}$ & 73.7 & $65.65 \%$ & 89.23 & 87.34 \\
\hline
\end{tabular}

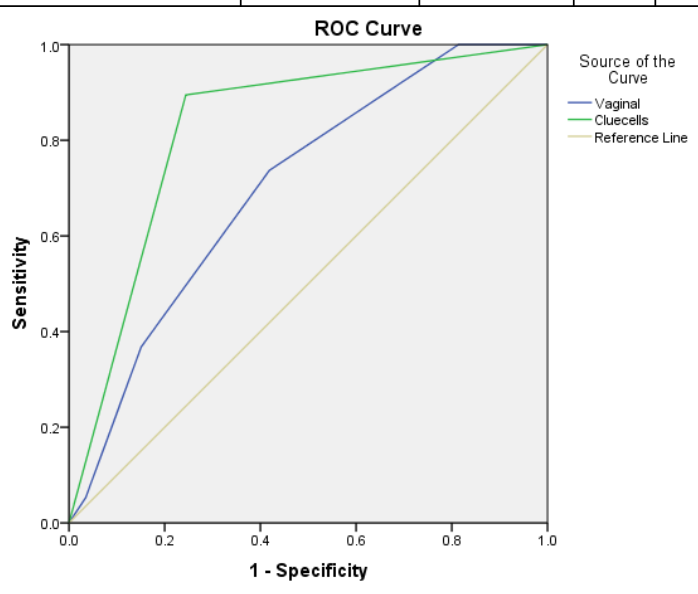

Diagonal segments are produced by ties

Graph 1: Diagnostic Accuracy Of Combintion Of Two Criteria (vaginal Ph + Clue Cells)

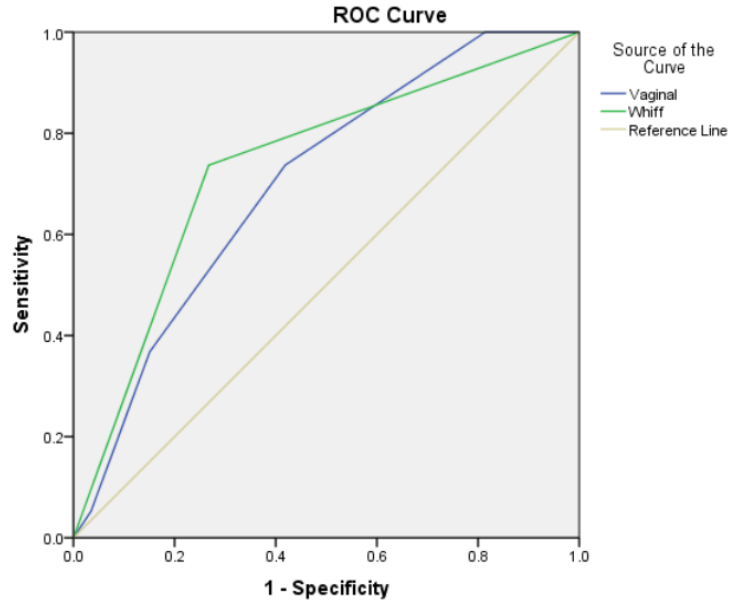

Diagonal segments are produced by ties.

Graph 2: Diagnostic Accuracy Of Combintion Of Two Criteria (vaginal Ph + Whiff Test)

\section{REFERENCES}

1. Mohammadzadeh, Farnaz et al. "Diagnostic value of Amsel's clinical criteric for diagnosis of bacterial vaginosis." Global journal of health science vol. 7,3 8-14. 29 Oct. 2014, doi:10.5539/gjhs.v7n3p8

2. Sha, Beverly E et al. "Utility of Amsel criteria, Nugent score, and quantitative PCR for Gardnerella vaginalis, Mycoplasma hominis, and Lactobacillus spp. for diagnosis of bacterial vaginosis in human immunodeficiency virusinfected women." Journal of clinical microbiology vol. 43,9 (2005): 4607-12. doi:10.1128/JCM.43.9.4607-4612.2005

3. Hemalatha, $\mathrm{R}$ et al. "Evaluation of vaginal $\mathrm{pH}$ for detection of bacterial vaginosis." The Indian journal of medical research vol. 138,3 (2013): 354-9.

4. Mirmonsef, Paria et al. "The effects of commensal bacteria on innate immune responses in the female genital tract." American journal of reproductive immunology (New York, N.Y. : 1989) vol. 65,3 (2011): 190-5. doi:10.1111/j.16000897.2010.00943.x

5. UDAYALAXMI, GOPALAKRISHNA BHAT SUBBANNAYYA KOTIGADD, SHALINI SHENOY. COMPARISON OF THE METHODS OF DIAGNOSIS OF BACTERIAL VAGINOSIS. Journal of Clinical and Diagnostic Research [serial online] 2011 June [cited: 2019 Aug 8 ]; 5:498-501.

6. Krieger JN, Tam MR, Stevens CE, Nielsen IO, Hale J, Kiviat NB, et al. Diagnosis of trichomoniasis. Comparison of conventional wet-mount examination with cytologic studies, cultures, and monoclonal antibody staining of direct specimens. JAMA. 1988 Feb 26. 259(8):1223-7.

7. Sobel JD. What's new in bacterial vaginosis and trichomoniasis?. Infect Dis Clin North Am. 2005 Jun. 19(2):387-406 